\title{
Portal Virtuhab - Sustentabilidade em projetos de engenharia, arquitetura e design
}

\section{Portal Virtuhab - Sustainability in Engineering Design, Architecture and Design}

Paulo Cesar Machado Ferroli ${ }^{1}$

Lisiane Ilha Librelotto ${ }^{2}$ 


\section{Resumo}

$\mathrm{Na}$ abordagem atual, a concepção de novos produtos exige a união de fatores técnicos, estéticos, econômicos e ambientais. Neste contexto, a escolha dos materiais e dos processos construtivos passa a ser integrado ao projeto, planejado durante todo o ciclo de vida do produto. A eficácia desta escolha depende da eficiência correlacionada dos fatores anteriormente citados. Encontrar esse conjunto de informações é tarefa árdua e muitas vezes decepcionante. A inclusão da sustentabilidade traz mais uma variável na já complexa equação, de modo que o projetista necessita ter, disponivel, estudos sobre a sustentabilidade dos diversos materiais existentes. Esse artigo apresenta uma proposta de suprir essa lacuna, mediante a utilização de uma materioteca com um novo conceito, onde além de amostras de materiais e informações técnicas, apresenta um relatório completo sobre a sustentabilidade econômica, social e ambiental de cada material. Os resultados obtidos até o momento da pesquisa aqui relatada demonstraram ser possivel fornecer aos projetistas uma análise da sustentabilidade relativa de cada material em comparação com outros similares, proporcionando um conjunto relevante de informações projetuais.

Palavras-Chave: sustentabilidade; design; engenharia; arquitetura; portal
$\mathrm{Na}$ abordagem atual, a concepção de novos produtos exige a união de fatores técnicos, estéticos, econômicos e ambientais. Neste contexto, a escolha dos materiais e dos processos construtivos passa a ser integrado ao projeto, planejado durante todo o ciclo de vida do produto. A eficácia desta escolha depende da eficiência correlacionada dos fatores anteriormente citados. Encontrar esse conjunto de informações é tarefa árdua e muitas vezes decepcionante. A inclusão da sustentabilidade traz mais uma variável na já complexa equação, de modo que o projetista necessita ter, disponível, estudos sobre a sustentabilidade dos diversos materiais existentes. Esse artigo apresenta uma proposta de suprir essa lacuna, mediante a utilização de uma materioteca com um novo conceito, onde além de amostras de materiais e informações técnicas, apresenta um relatório completo sobre a sustentabilidade econômica, social e ambiental de cada material. Os resultados obtidos até o momento da pesquisa aqui relatada demonstraram ser possível fornecer aos projetistas uma análise da sustentabilidade relativa de cada material em comparação com outros similares, proporcionando um conjunto relevante de informações projetuais.

Keywords: Sustainability; design; engineering; architecture; portal

${ }^{1}$ Engenheiro Mecânico, Doutor em Engenharia de Produção, professor do design, adj. 3, CCE -UFSC - Brasil ferroli@cce.ufsc.br

${ }^{2}$ Engenheiro Civil, Doutora em Engenharia de Produção - Brasil lisiane.librelotto@gmail.com 


\section{Introdução}

A garantia da sustentabilidade em um projeto de produto envolve o equilíbrio entre três dimensões: econômica, social e ambiental. Deve-se buscar o lucro que permita a satisfação dos interesses de todos os intervenientes do processo; os investidores devem ter o retorno financeiro; a comunidade local deve usufruir dos benefícios da atividade realizada; os funcionários devem ter seu retorno em qualidade de vida e equidade social, e tudo isso, não deve prejudicar o meio ambiente, do qual todos necessitam para sobreviver. Kubota e outros [1] destacam a importância deste equilíbrio: "as questões ambientais precisam agora ser consideradas como parte integrante do processo global de desenvolvimento de produtos".

A sustentabilidade é um dos assuntos mais discutidos atualmente e deixou de ser novidade. Envolve as mais diversas áreas do conhecimento: das ciências sociais aplicadas às engenharias, passando pelas ciências humanas, exatas, etc.. No aspecto profissional, estar ciente e atualizado sobre o tema tornou-se cada vez mais importante. Espera-se atualmente que cada pessoa seja capaz de reconhecer sua parcela de responsabilidade, do que pode fazer para contribuir, independente do tipo de atividade profissional exercida. A sustentabilidade atua como um elo social, no qual cada ação individual tem efeito compartilhado por todos.

Hansen e outros [2] explicam que a conscientização da sociedade por um desenvolvimento sustentável uniu-se à busca pelo aumento do desempenho ambiental das organizações. Isso estimulou a evolução de uma linha de pensamento que prima avaliar o saldo ambiental de produtos e serviços, por meio de uma abordagem ampla das inter-relações entre os sistemas e o meio ambiente. Passou a ser conhecida por Avaliação do Ciclo de Vida (ACV).

Tanto no meio acadêmico quanto no industrial, o tema "sustentabilidade" tem sido inserido gradualmente. É difícil encontrar no mercado algum evento (capacitações, treinamentos, programas de pós-graduação, cursos de aperfeiçoamento, palestras, simpósios, feiras, etc.) que não incluam a questão da sustentabilidade como foco de discussão. Outra constatação que comprova o aumento do interesse do tema é na quantidade de artigos enviados aos congressos, eventos e periódicos, onde a área da sustentabilidade teve acréscimo considerável nas publicações. Contudo, apesar desse incremento, a compreensão necessária do tema ainda esbarra em dois aspectos interligados: a complexidade dos fatores envolvidos, e o desconhecimento das variáveis e condicionantes interligados.

Conforme destacam Kubota e outros [1], a maioria dos artigos (63\%) são de caráter teórico, que propõe métodos e modelos conceituais de desenvolvimento de produtos, considerando aspectos de projeto técnico alinhados a aspectos do ecodesign, por vezes denominado design sustentável, seguidas de estudo ou análise de casos para a avaliação dos modelos propostos. Há, portanto, carência de abordagens e aplicações práticas, preferencialmente sob a forma de extensão universitária, fortalecendo o vínculo pesquisa - ensino - extensão.

Este artigo mostra ações conjuntas realizadas na universidade, envolvendo cursos de engenharia, arquitetura e design, que objetivam contribuir na resolução da 
problemática acima descrita. Mostra resultados já obtidos relacionados à construção de uma materioteca com ênfase na sustentabilidade, disponibilizada em ambiente virtual e físico.

\section{Design e sustentabilidade - considerações}

A construção civil um dos setores que mais contribui para a formação do PIB nacional, de forma direta e indireta (impacto econômico). O setor é notavelmente responsável por nortear as políticas públicas para redução do déficit habitacional (impacto social) e é elemento decisivo na preservação do meio ambiente (impacto ambiental). Dado o percentual de resíduos depositados em aterros municipais, incluindo até as questões de deficiência de saneamento e ocupação irregular de áreas verdes, a construção civil é um setor industrial que carece da avaliação do posicionamento das empresas quanto à sustentabilidade. Em virtude disso, foi o setor escoIhido como ponto de partida para a implementação da proposta aqui apresentada.

Projeto é uma atividade complexa. Isso não é novidade, pois envolve conhecimentos gerais e específicos de várias áreas, sendo por essência, multidisciplinar. É caracterizado pela necessidade de integração e correlações de fatores estéticos, mercadológicos, financeiros, ecológicos, produtivos e ergonômicos.

O projeto de novos produtos, de acordo com Manzini e Vezzoli [3] deve, em uma situação ideal, compreender o sistema produto-serviço, não se limitando apenas ao produto físico (definido por material, forma e função). Dessa forma o resultado de um projeto seria um conjunto integrado de produto, serviço e comunicação.

Dentro dessa linha de pensamento os autores destacam que o projeto deve "ligar" o tecnicamente possível com o ecologicamente necessário atuando dentro de quatro níveis de interferência: redesign ambiental de produtos já existentes; projeto de novos produtos para substituição dos atuais; projeto de novos produtos - serviços intrinsecamente sustentáveis; e proposta de novos cenários para um novo estilo de vida sustentável (figura 1).

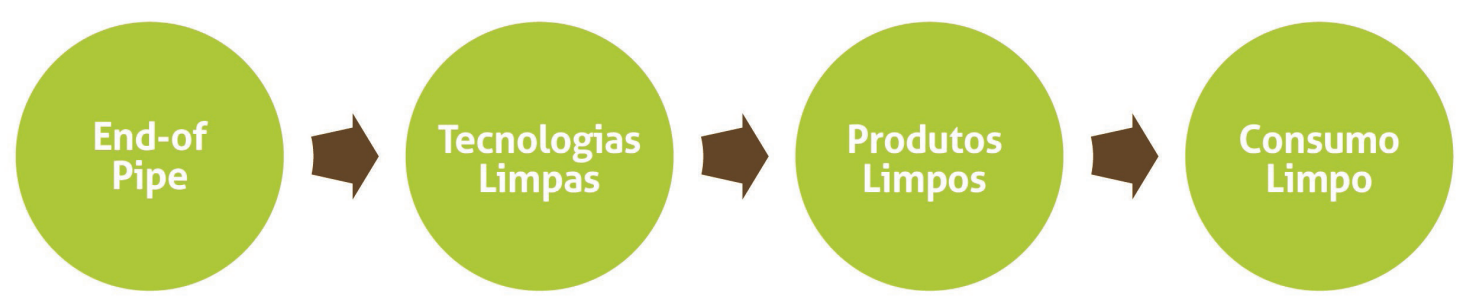

Figura 1:Evolução projeto e meio-ambiente. Fonte adaptada: Manzini e Vezzolli [3]

Ainda segundo Manzini e Vezolli [3], no estado atual da atividade projetual, a atuação profissional está, quase na totalidade dos casos, restrita aos dois primeiros níveis citados. Embora úteis, estes se mostram insuficientes para atingir a sustentabilidade ambiental (garantida apenas pela inclusão dos outros dois níveis - Design for Sustainability). 
Sob esse enfoque, o projeto englobando os preceitos da sustentabilidade passa a ser, senão a única, ao menos a mais relevante solução possível para que ocorra a união entre a filosofia da melhoria contínua com a necessidade cada vez maior da preservação dos recursos naturais, qualidade de vida do homem e ao capitalismo vigente.

O presente projeto foi baseado no modelo ESA, encontrado em Librelotto [4], e que foi usado inicialmente para análise da sustentabilidade na indústria da construção civil. No referido modelo, através da análise conjunta das pressões do mercado, frente ao desempenho da empresa e de sua conduta, classificaram-se empresas de acordo com termos predeterminados: derrotada, sofrível, indiferente, responsável, oportunista e pioneira. Além da aplicação direta da autora, o modelo foi utilizado em duas dissertações de mestrado, ambas também com foco na construção civil, e duas pesquisas de iniciação científica na área de mobiliário, totalizando cinco estudos de caso.

De posse dos resultados obtidos, analisando-se a potencialidade demonstrada nos estudos de caso, aplicou-se o modelo ESA na análise da sustentabilidade dos materiais utilizados na confecção de produtos físicos para design, arquitetura e engenharia civil (modelos volumétricos e protótipos), adaptando o método conforme a especificidade da área.

A figura 2 mostra as alterações realizadas no modelo ESA com vistas a aplicação específica em modelos volumétricos e protótipos. Os resultados desta pesquisa inicial foram fundamentais para montagem da metodologia de pesquisa utilizada para compor os dados da materioteca. Observa-se pela figura 1 que os eixos econômico e ambiental foram subdivididos em três partes e o eixo social em duas. O posicionamento se dá através da composição ( $x, y, z)$, com escalas de 0 a 10,0.
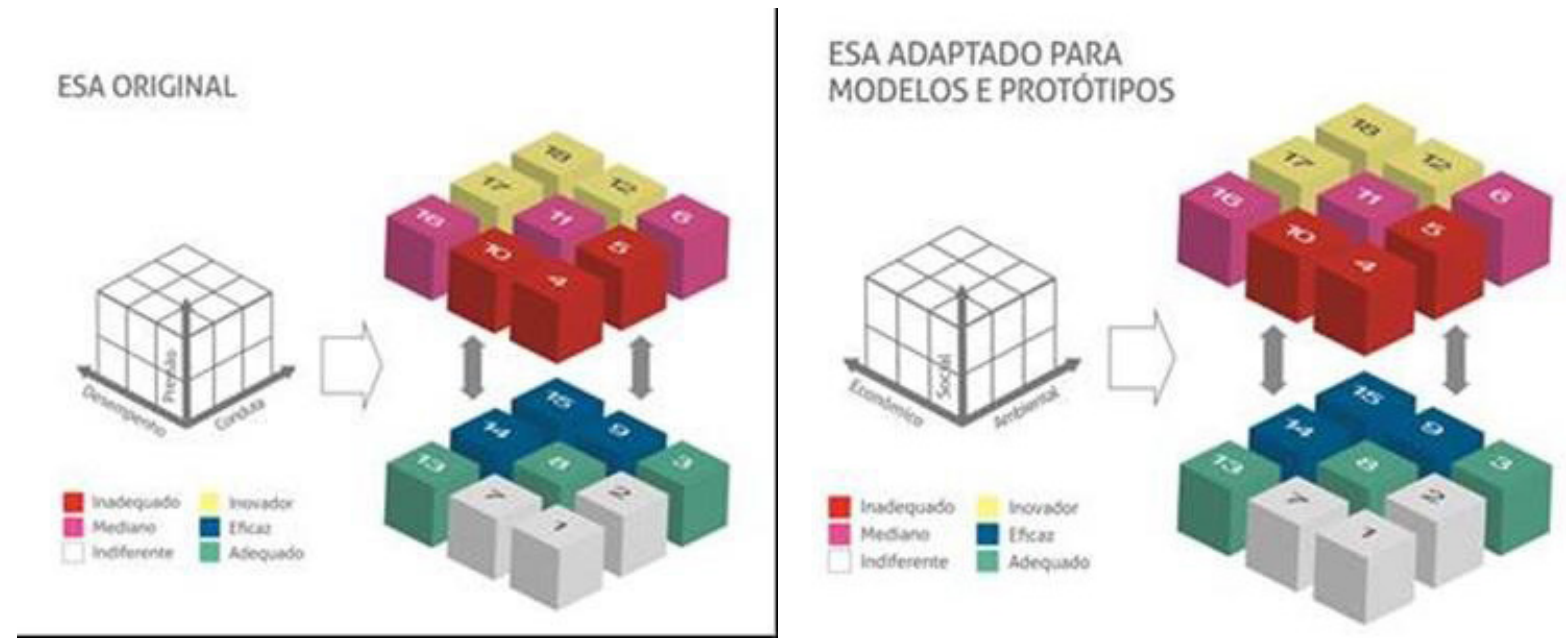

Figura 2:Modelo ESA. Fonte adaptada: Librelotto [4]

Uma das principais considerações na pesquisa foi a busca de prover empresas de menor porte a soluções em termos de análises da sustentabilidade não muito caras, sem haver a necessidade de aquisição de softwares importados ou medições de difícil acesso. Depois de realizar a pesquisa bibliográfica e de campo, os valores estipulados nas planilhas de classificação foram divididos em três grupos principais (originados do modelo ESA) e cada qual subdivididos novamente em dois quesitos básicos: 
- Grupo 1 - Fatores Econômicos:

1. material de confecção do modelo: preço de aquisição do material (R\$); quantidade de material utilizado $(\mathrm{kg})$; e porcentagem de aproveitamento do material considerando dimensões comerciais disponíveis no mercado (\%);

2. processo de fabricação: quantidade de ferramentas necessárias (unidades); custo de energia elétrica (kwh x custo do kwh, em $\mathrm{R} \$$ ); e tempo de fabricação do modelo (minutos);

- Grupo 2 - Fatores Sociais:

1. material de confecção do modelo: quantidade de fornecedores na região (unidade); disponibilidade do material, ou seja, tempo de espera para efetivar a compra (dias); e existência na região de materiais alternativos (aproximadamente de mesmo custo) na impossibilidade de uso do material de primeira escolha (sim ou não).

2. processo de fabricação: possibilidade de geração de renda para a região, ou seja, se a matéria-prima empregada no modelo é fabricada na região (sim ou não); quantidade de empresas capazes de fabricar a matéria-prima empregada no modelo na região (quantidade); e capacitação da mão-de-obra na região especializada na produção da matéria-prima empregada na fabricação do protótipo (medida de observação qualitativa).

- Grupo 3 - Fatores Ambientais:

1. material de confecção do modelo: possibilidade de reciclagem do material usado no protótipo (\% de material que pode ser reciclado); possibilidade de reaproveitamento do material usado no protótipo (\% de material que pode ser reaproveitado); e origem da matéria-prima (virgem, reciclada ou mista).

2. processo de fabricação: gasto energético total na fabricação do protótipo (R\$); quantidade de subprodutos sem utilidade gerados no processo fabril (kg); e quantidade de subprodutos que podem ser vendidos para reciclagem ou reaproveitamento gerados no processo fabril $(\mathrm{kg})$.

$\mathrm{Na}$ aplicação do ESA, as notas foram atribuídas mediante comparações quantitativas e qualitativas com outros possíveis materiais que poderiam ter sido utilizados para a construção do protótipo, respeitando-se aos requisitos técnicos e estéticos. Observa-se que, para efeito do proposto, o modelo volumétrico ou protótipo desenvolvido com o uso de determinado material foi comparado com outros dois possíveis materiais. Limitou-se em dois somente para efeitos da referida pesquisa, ressaltandose, no entanto, que não existem limites determinados para uma aplicação prática.

A proposta foi testada em diversos projetos. A figura 3 mostra dois destes projetos, para fins ilustrativos. No primeiro, trata-se de um modelo funcional em escala reduzida. Este modelo foi ser utilizado para estudar uma proposta de habitação que pode ser implementada em casos de reassentamentos em comunidades que sofreram catástrofes ambientais, como inundações, principalmente.

No segundo caso, tem-se um modelo desenvolvido para testar um material alternativo para construção das paredes.

Baseando-se nestes resultados preliminares, foram iniciados os procedimentos metodológicos para aplicação do modelo ESA nos materiais disponibilizados na materioteca e colocados no portal Virtuhab. 

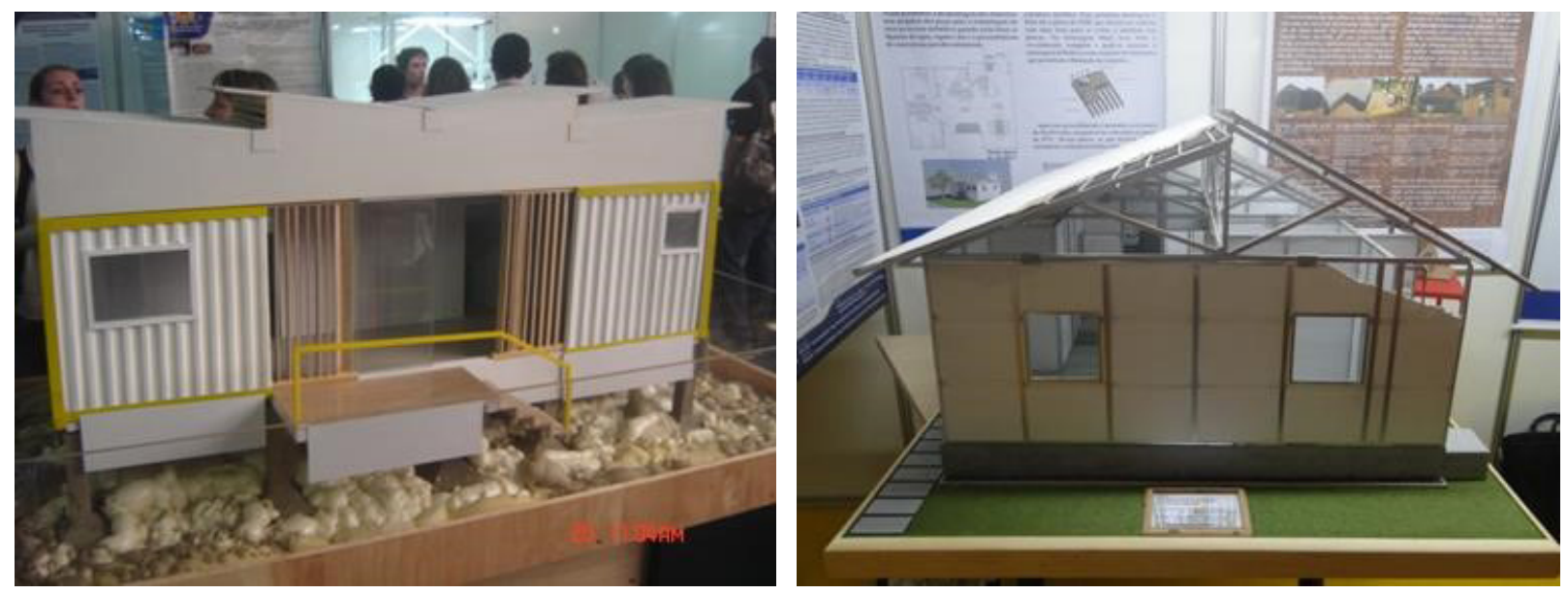

Figura 3: Demonstração de uso em modelos de escala reduzida

\section{Montagem da materioteca e portal virtuhab - procedimentos metodológicos}

$\mathrm{Na}$ execução do projeto relatado neste artigo, foi utilizada como ponto de partida a pesquisa bibliográfica para determinação do estado da arte do referido problema, seguida da pesquisa de campo (emprego de técnicas para coleta de dados e determinação de uma possível amostra). Seguiram a isso os procedimentos padrões de síntese das informações, composição de variáveis da sustentabilidade, elaboração dos requisitos de classificação dos materiais em virtude da sustentabilidade, escolha dos grupos de materiais nos quais se realizaram as análises, testes e procedimentos de validação.

Na parte inicial da pesquisa foi realizada a determinação das variáveis a serem consideradas e seus possíveis desdobramentos, seguido pelos meios de mensuração possíveis. Em virtude da temática abordada foi necessário trabalhar-se com variáveis qualitativas e quantitativas.

Os procedimentos metodológicos e estratégias de ação para realização desta pesquisa foram:

1) Definição dos conteúdos de materiais, processos de fabricação e sustentabilidade necessários para a montagem inicial da materioteca. Considerando-se o grande volume de materiais e processo fabris a eles relacionados, foi utilizada a classificação mostrada no quadro 1, estruturada segundo Lesko [5] e Ashby e Johnson [6]. A classificação proposta no quadro 1 poderá sofrer alterações à medida que novos materiais sejam incorporados na materioteca, da mesma forma que os processos de fabricação, e teve como base conceitual Hudson [7].

2) Construção do mapa conceitual dos conteúdos básicos de materiais, processos de fabricação e sustentabilidade.

O mapa conceitual foi sendo formado mediante a interligação dos dados obtidos na pesquisa bibliográfica com os obtidos pela pesquisa de campo. A pesquisa de campo englobou visitas a materiotecas existentes, aplicação de questionários e entrevistas a alunos e professores que utilizam materiotecas (tanto físicas quanto virtuais) e observações práticas nas disciplinas de projeto de produto. A etapa projetual escolhida foi a de detalhamento da alternativa escolhida, quando os grupos de 
estudantes precisam definir os materiais e processos fabris de suas criações. Através do mapa conceitual foi possível estabelecer algumas relações importantes entre os conceitos fundamentais de materiais, processos de fabricação e sustentabilidade aplicados ao projeto de produtos, propriedades e aplicabilidade sob o enfoque do modelo ESA.
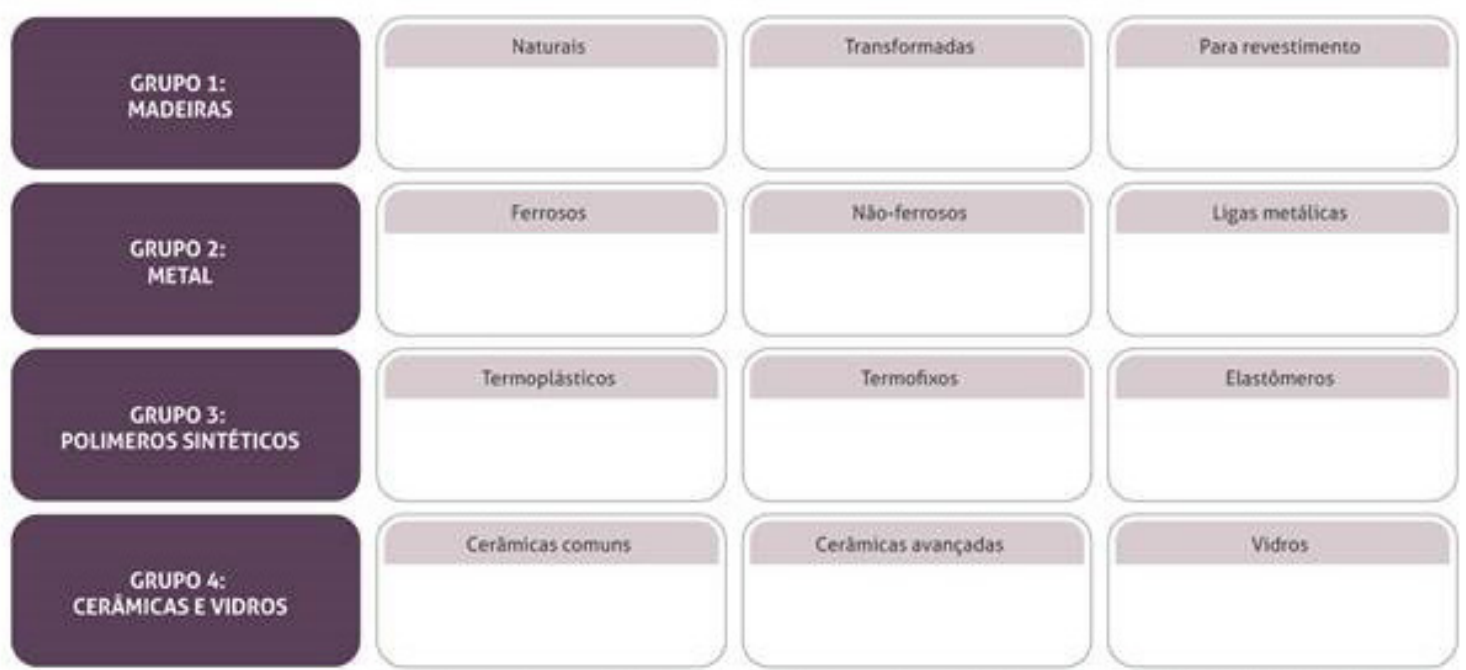

Ligas metalicas
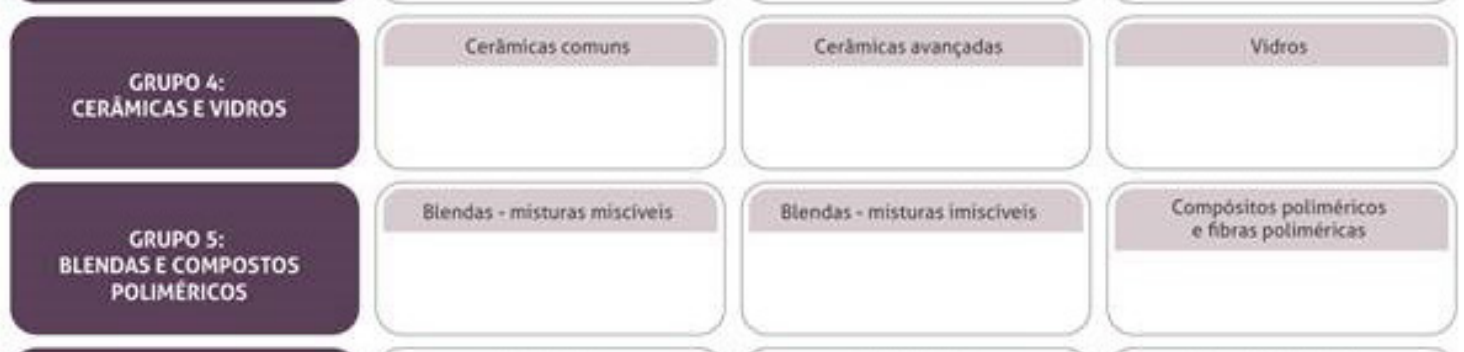

Elastómeros

Blendas - misturas imisciveis
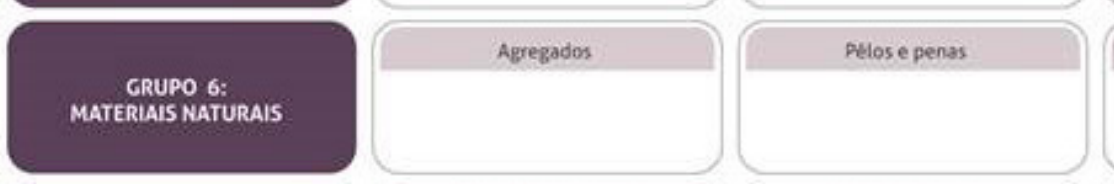

Compositos poliméricos e fibras potimérikas
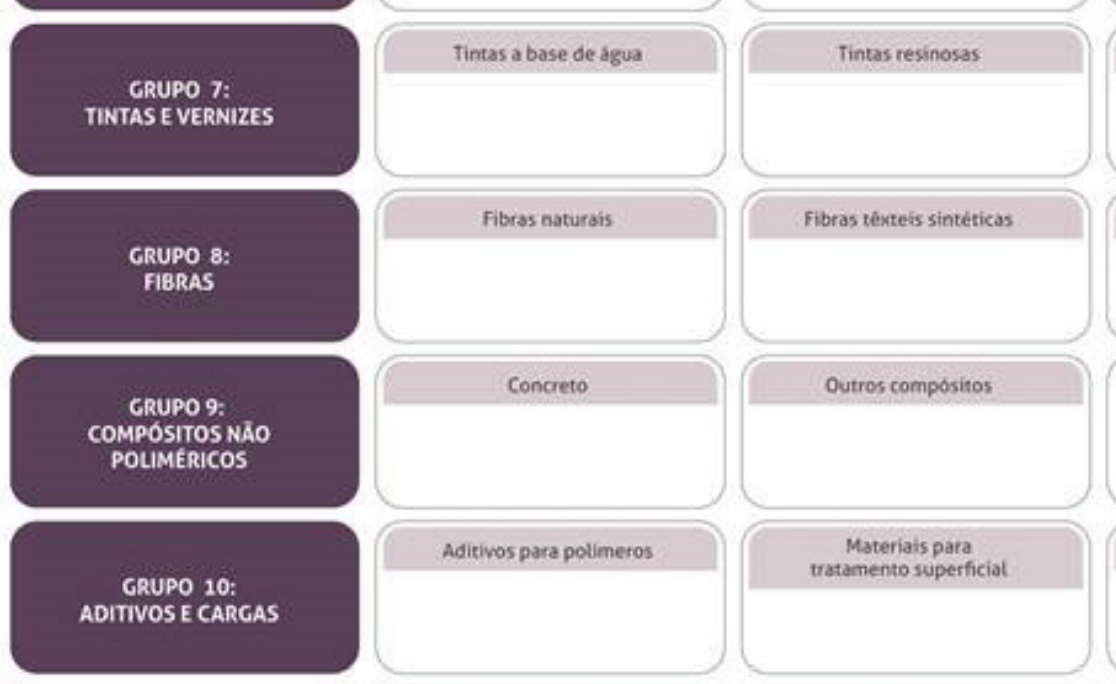

Aditivos para polimetos

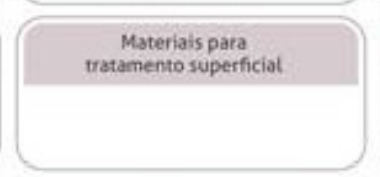

Gemas e minérios
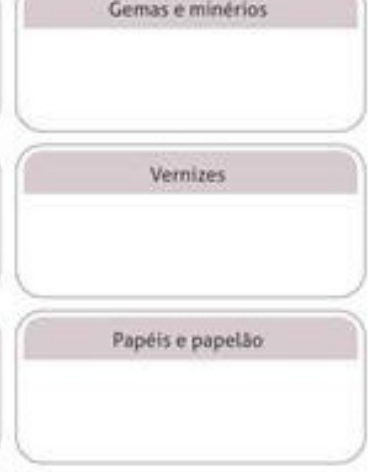

OUTROS MATERIAIS

Nanotecnologis

Materiais com "menoria"

Quadro 1 Classificação dos materiais expostos na materioteca

3) Escolha do padrão a ser utilizado para a confecção das planilhas demonstra- 
Portal Virtuhab - Sustentabilidade em Projetos de Engenharia,

Arquitetura e Design

tivas.

Em virtude da grande diversidade de informações disponíveis dos diferentes materiais, foi necessária a elaboração de uma planilha padrão, sem a qual seria muito difícil ao projetista fazer a comparação dos quesitos social, econômico e ambiental, inviabilizando a aplicação do ESA. Embora já se tenha definido algumas propostas para o padrão, a grande diversidade de materiais está dificultando essa etapa. O quadro 2 mostra o modelo atualmente utilizado.

MATERIOTECA - NULLAM - Banco de Dados da Sustentabilidade dos Materiais

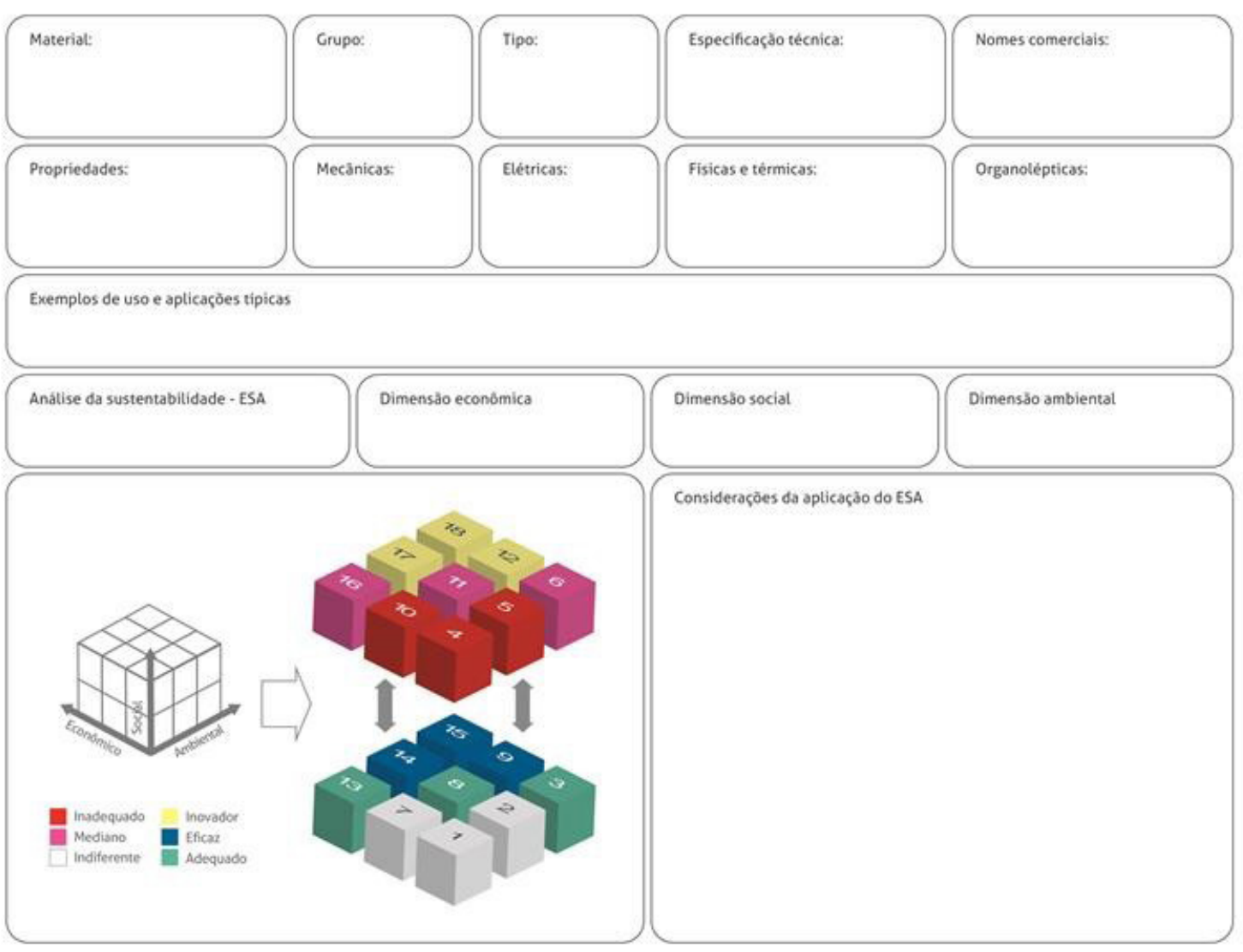

Quadro 2. Modelo utilizado atualmente na materioteca.

O quadro 2 acompanha cada material exposto na materioteca. Por exemplo, considerando como material básico o aço inoxidável, tem-se:

- material: aço inoxidável (C - Fe - Ni - Cr)

- grupo: austenítico

- tipo: normal

- especificação técnica: AISI 304

- nome comercial: aço inox

Em propriedades mecânicas, são disponibilizados dados como ductilidade, dureza e tenacidade (dentre outras); em propriedades elétricas o projetista irá encontrar dados, por exemplo, sobre resistividade; as propriedades físicas e térmicas englobam 
densidade, calor específico e condutividade, entre outras e as propriedades organolépticas são mais aplicadas para análise sistêmica do projeto e trazem informações referentes a cor, sabor, odor e brilho.

Em exemplos de uso e aplicações típicas são mostradas fotos do material aplicado em diversos ambientes, com variações de acabamento e tratamentos superficiais.

$\mathrm{Na}$ análise da sustentabilidade são relacionados todos os dados pertinentes a cada dimensão. O gráfico ESA é demonstrado com comparação a dois materiais similares, um do mesmo grupo e outro de outro grupo (apenas para exemplificação). Por exemplo, o aço inoxidável AISI 304 apresenta um gráfico ESA de comparação com o aço carbono SAE 1020 fosfatizado e pintado e com o nylon, PA 6.6. Se o usuário desejar obter o gráfico de comparação com outro material deverá preencher os dados dos materiais pesquisados no site, que irá gerar o gráfico. Cabe ressaltar que essa etapa do projeto ainda está em implementação. A figura 4 ilustra uma parte do portal.

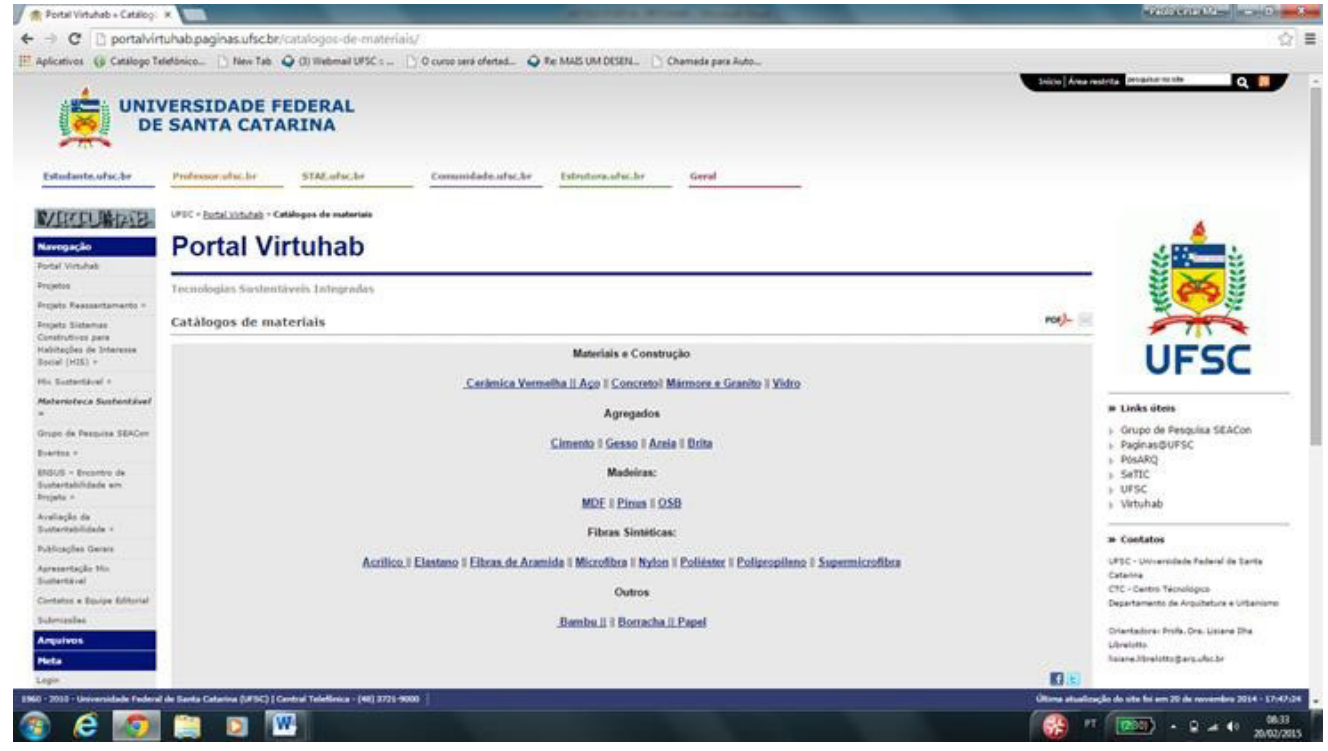

Figura 4. Materioteca digital disponibilizada no portal.

\section{Aplicação do modelo ESA}

Esta etapa se refere a aplicação propriamente dita do modelo ESA em cada um dos materiais da materioteca. Aqui, cada material classificado anteriormente é analisado utilizando-se para isso das planilhas já preenchidas nas etapas anteriores.

A apresentação consiste da amostra (ou conjunto de amostras) propriamente dita, relatório individual do material e gráfico demonstrativo. Por limitações físicas, não é possível apresentar o gráfico demonstrativo de todas as possíveis combinações, por isso a necessidade da parte virtual da materioteca, onde o projetista poderá fazer as devidas simulações, comparando entre si os gráficos gerados.

O relatório individual de cada material é o resultado direto das etapas anteriores, enquanto que os gráficos demonstrativos apresentados servem somente para orientação de procedimento. O gráfico apresenta, ao final, um "índice" da sustentabilidade alcançada por determinado material, que permite ao projetista uma medida quantitativa de comparação, tornando possível a comparação de determinado material com 
outros, do mesmo grupo ou de grupo distinto, sob o aspecto da sustentabilidade.

O próximo item deste artigo apresenta um estudo de caso mostrando a obtenção do índice relativo a sustentabilidade de materiais usados na construção de um modelo.

\section{Estudo de caso - aplicação do modelo esa - resultados}

A materioteca atualmente em construção já possui mais de 700 amostras, com informações atualizadas nas planilhas demonstrativas. O projeto intitulado Nullam - Banco de Dados da Sustentabilidade dos Materiais, atualmente em andamento, deverá suprir a lacuna referente a parte virtual da materioteca, tendo como resultado, além da conclusão do website, a programação do software que permitirá a elaboração mais simplificada do gráfico ESA.

No momento, os gráficos ainda são elaborados utilizando-se o Excel. A figura 5 mostra a materioteca (parte física).

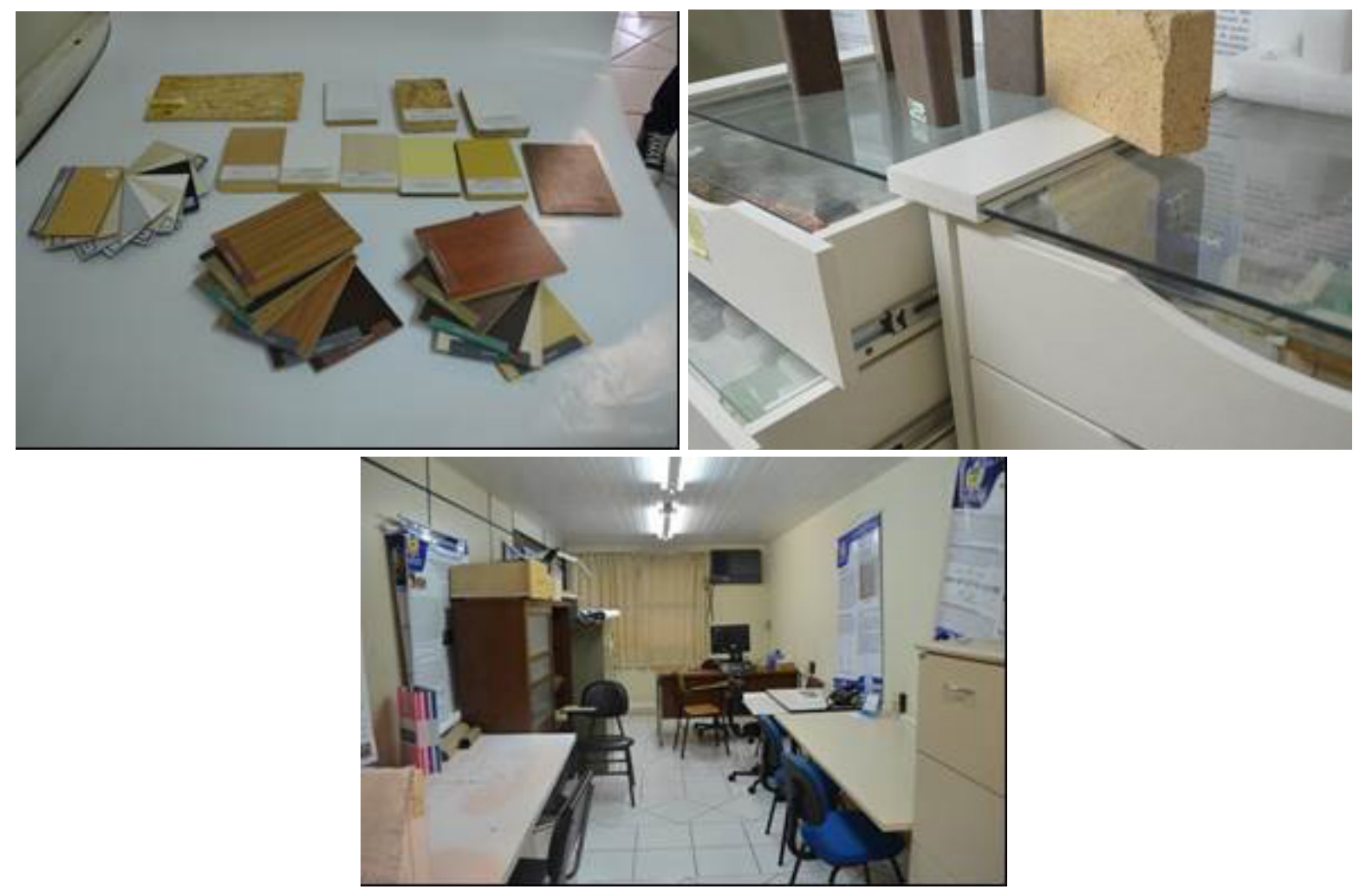

Figura 5. Materioteca - parte física.

Todas as atividades são realizadas por bolsistas de iniciação científica, extensão e mestrado, orientados por dois professores doutores. A comunicação é realizada através do Dropbox e reuniões semanais são realizadas para verificação das metas preestabelecidas.

Durante os anos 2013-2014, quando o projeto iniciou, os alunos bolsistas foram também responsáveis, além das atividades inerentes as pesquisas em andamento, pelo projeto dos móveis necessários ao espaço e das marcas vinculadas ao projeto: Virtuhab (portal que abriga os projetos do grupo), Materioteca Sustentável e Mix Sustentável (periódico a ser lançado). A figura 6 mostra as marcas desenvolvidas pela 
equipe de design gráfico do grupo.

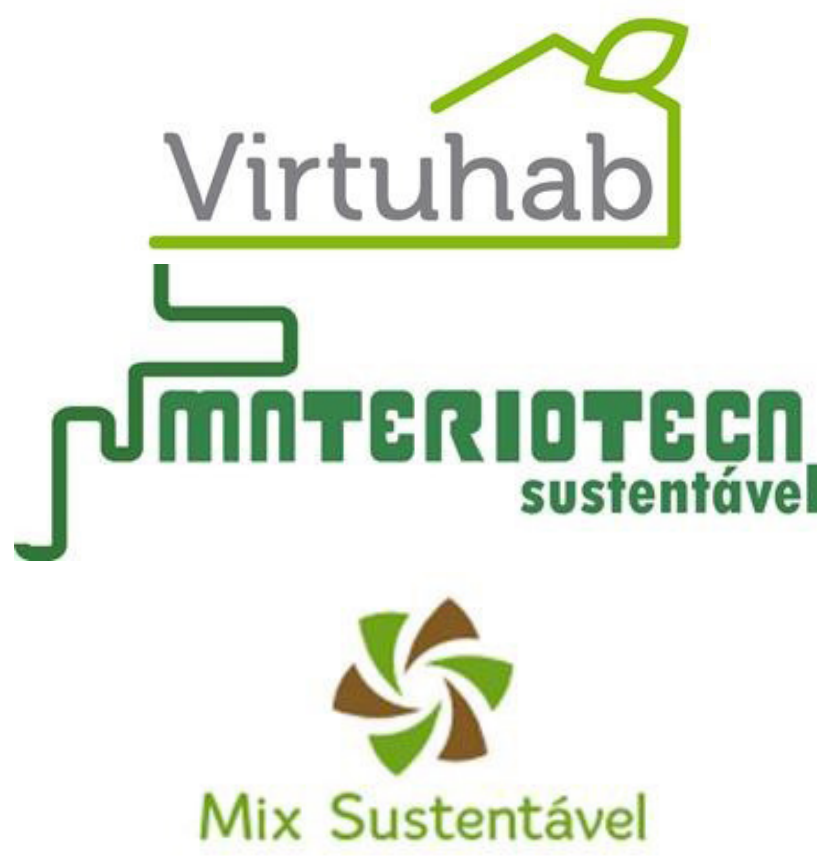

Figura 6. Marcas desenvolvidas para o projeto.

O modelo ESA foi testado em várias simulações na materioteca. Esse item demonstra o teste na construção das sapatas usadas no modelo mostrado na figura 2 deste artigo. Para isso, foi necessário separar-se em duas análises: a primeira referindo-se ao material de construção das fôrmas, onde as opções eram madeira de compensado, papelão do tipo couro e madeira natural do tipo Pinus. Na segunda análise, considerou-se o material para preenchimento das sapatas, testando-se concreto, gesso e resina de poliéster com opções. A figura 7 mostra uma etapa da construção desta parte do modelo

Considerações sobre os dados coletados para análises:

- o fator E1 refere-se somente ao preço de aquisição do material. Foi pesquisado em três fornecedores. O valor colocado na tabela considera a média dos fornecedores e a porcentagem relativa ao peso de material efetivamente utilizado. A questão do reaproveitamento ou não das sobras é analisada em outro quesito.

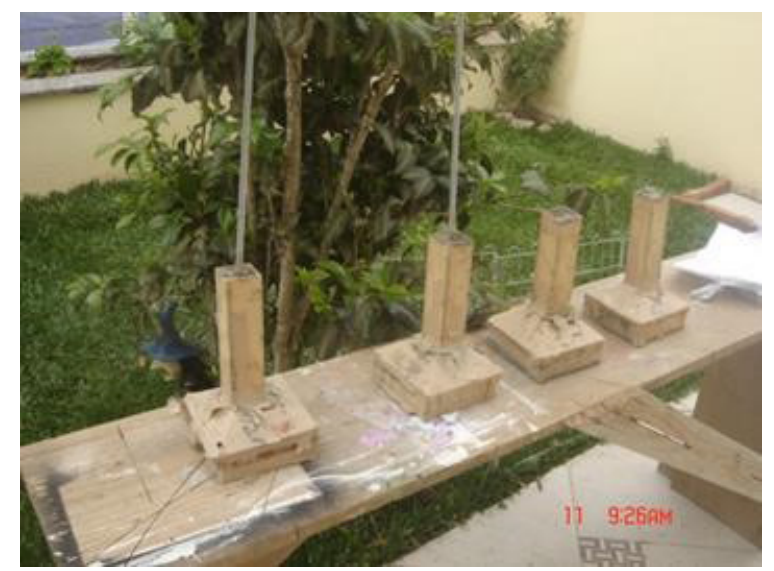

Figura 7. Modelos confeccionados para teste do ESA. 
- o fator E2 refere-se somente ao peso de material utilizado, que foi medido após confecção do modelo.

- o fator E3 refere-se ao aproveitamento do material com relação a dimensões comerciais.

- o fator E4 diz respeito somente ao número de ferramentas empregadas na confecção de cada modelo, e foi simplesmente contada.

- o fator E5 refere-se ao custo gasto com energia, medida de acordo com o tempo de produção de cada parte do modelo.

- o fator E6 encerra esse primeiro grupo e refere-se ao tempo gasto na confecção de cada modelo. O tempo gasto na confecção do molde, neste caso, foi contabilizado para todos os modelos.

- o fator S1 contabiliza os fornecedores da região. Considerou-se a região da Grande Florianópolis, incluindo as cidades de São José, Palhoça e Biguaçu.

- o fator S2 trata do tempo de espera.

- o fator S3 verifica a possibilidade ou não da substituição do material verificado por outro semelhante, que tenha disponível na região.

- o fator S4 analisa se há a possibilidade de geração de renda para a região.

- o fator S5 analisa a existência, ou não, de empresas capacitadas a fabricar a matéria-prima utilizada na região.

- o fator S6 refere-se a existência e capacidade de mão-de-obra para o material considerado. A análise desse fator, no presente caso, foi qualitativa.

- o fator A1 analisa a possibilidade de reciclagem do material.

- o fator A2 refere-se a possibilidade de reaproveitamento.

- o fator A3 analisa a origem da matéria-prima.

- o fator A4 calcula o gasto energético total no processamento da matéria-prima. Como os modelos foram construídos em escala pequena, esse fator teve um impacto muito pequeno.

- o fator A5 analisa a quantidade de subprodutos sem utilidade gerados.

- o fator A6 analisa a possibilidade de venda dos subprodutos gerados.

Os quadros 3 e 4 mostram a aplicação do ESA-MOD.

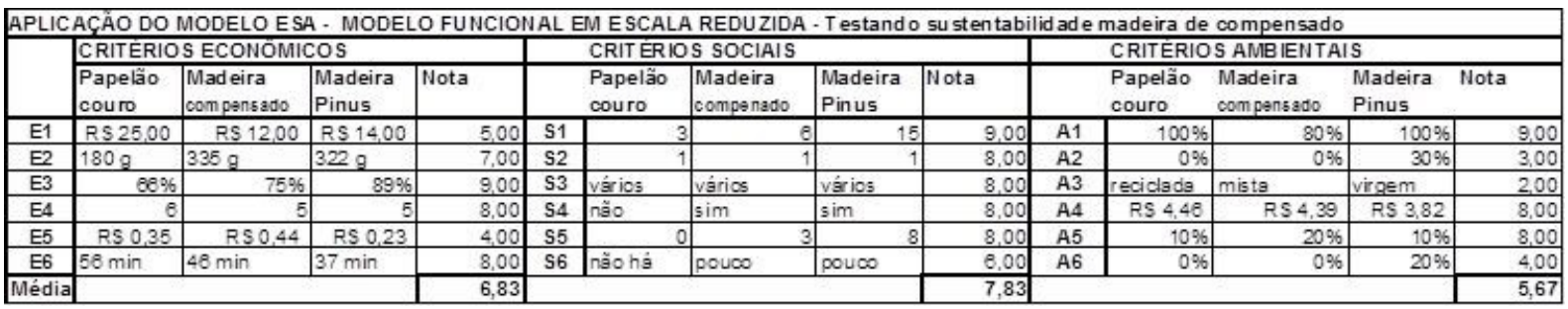

Quadro 3. Aplicação do ESA-MOD adaptado para determinação da sustentabilidade do material das formas.

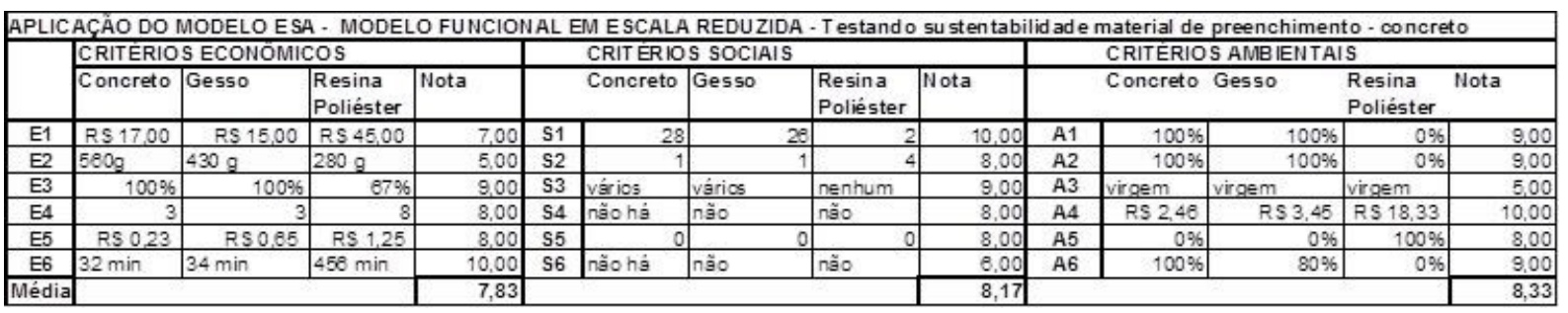

Quadro 4. Aplicação do ESA-MOD para determinação da sustentabilidade do material de preenchimento. 


\section{Considerações finais}

A escolha dos materiais em design é mais do que a consideração de atributos técnicos e produtivos. Um bom produto precisa atender necessidades de todos os grupos de usuários, envolvendo aspectos produtivos, econômicos, ergonômicos, sociais, ambientais e estéticos, e os materiais utilizados no produto devem estar em conformidade com estes aspectos.

O modelo ESA, originalmente concebido para aplicação na construção civil, pode ser adaptado a contento no intuito de fornecer aos designers um modo quantitativo / qualitativo de avaliar a sustentabilidade nas dimensões econômica, social e ambiental.

Para a realização dos experimentos práticos, utilizou-se dos trabalhos desenvolvidos por alunos de design, arquitetura e engenharia civil, bolsistas de iniciação científica, mestrandos e doutorandos. Foram escolhidos aleatoriamente alguns modelos volumétricos para teste e validação da adaptação original do modelo ESA, dos quais apena um foi mostrado neste artigo.

Optou-se pelo uso de modelos volumétricos, pois utilizam poucos materiais, o que facilitou a posterior aplicação na materioteca. Pela aplicação vista, pode-se enumerar as seguintes considerações:

- a adaptação do modelo ESA desenvolvido por Librelotto (2009) mostrou-se satisfatório para análise dos materiais, permitindo uma abordagem global da sustentabilidade;

- o preenchimento correto das planilhas originadas é muito importante. Devido a natureza das variáveis, pequenas oscilações podem alterar o posicionamento no paralelepípedo de classificação, podendo ocasionar conclusões precipitadas e incorretas;

- é necessário novos estudos propondo ponderação das variáveis sob a forma de pesos, testando-se a ferramenta GUT (Gravidade - Urgência - Tendência) para que se possam analisar caso a caso as particularidades de cada material.

Como recomendações para futuros trabalhos, deve ser observado que o modelo ESA foi constituído objetivando uma aplicação na construção civil. Os autores desse artigo perceberam no ESA uma potencialidade para analisar a sustentabilidade de qualquer produto. Há de se considerar, no entanto, as características próprias de cada setor. Devido a isso, o modelo ESA adaptado para uso em análises de materiais para a materioteca, deve ser testado com mais profundidade. Também é necessária a elaboração de um conjunto de diretrizes que possam orientar o designer (ou equipe de projeto) ao melhor posicionamento das variáveis econômicas, sociais e ambientais no modelo gráfico do ESA.

\section{Referências}

[1] KUBOTA, F. I.; CAMPOS, L. M. de S.; MIGUEL, P. A. C. "Uma análise preliminar das contribuições da modularidade em produto ao eco-design". In: Revista Produção Online, Florianópolis, SC, v.14, n. 2, p. 560-592, abr./jun. 2014. 
[2] HAUENSTEIN, Deisi Maria; KINDLIEIN JÚNIOR, Wilson. Estruturação de uma Biblioteca de Materiais : "Materioteca" . Disponível em: http://www.lume.ufrgs.br

[3] MANZINI, Ezio e VEZZOLI, Carlo. O Desenvolvimento de Produtos Sustentáveis Os requisitos ambientais dos produtos industriais. São Paulo: EdUSP, 2008.

[4] LIBRELOTTO, Lisiane Ilha. "Modelo para Avaliação de Sustentabilidade na Construção Civil nas Dimensões Econômica, Social e Ambiental (ESA): Aplicação no setor de edificações". São Paulo: Blucher Acadêmico, 2009.

[5] LESKO, Jim. "Design Industrial - Materiais e Processos de Fabricação". São Palo: Edgard Blucher, 2004.

[6] ASHBY, Michael; JOHNSON, Kara. "Materiais e Design". Rio de Janeiro: Campus, 2011.

[7] HUDSON, Jennifer. Process - "50 Produts Designs from Concept to Manufacture". Laurence King Publishing Ltd, 2008. 